\title{
Cidade palco das transformações
}

ARANTES, Antonio A. Paisagens Paulistanas: transformações do espaço público. Campinas, SP: Editora da Unicamp. São Paulo: Imprensa Oficial, 2000.

\section{Nicole Kunze Rigon ${ }^{1}$}

A construção do Viaduto do Chá em São Paulo em 1892 foi um marco do processo de desenvolvimento urbano da cidade na virada do século e foi considerado nas décadas de 40 e 50 como símbolo da "metrópole que mais cresce na América Latina" (p. 46). Nos anos 80 foi inaugurada uma estação subterrânea de metrô no mesmo local tornando o viaduto um plano de circulação secundário da população. $\mathrm{O}$ viaduto que havia sido por tanto tempo um marco representativo da cidade estava desgastado e perdera seu protagonismo para uma estrutura de locomoção mais moderna. No entanto, resiste como importante símbolo afetivo do cenário da cidade construído na memória social.

Dos questionamentos decorrentes da modernização do espaço urbano e especialmente da construção desse novo espaço de circulação subterrânea na cidade surgiu, em 1983, o espetáculo "Passos na cidade". No intento de explorar juntamente aos habitantes da cidade os significados e representações imbricados nos monumentos da cidade foi que se desenvolveu sob a coordenação de Antonio Arantes o espetáculo a céu aberto que convidava toda a população a se deslocar pelo palco - a cidade de São Paulo - e no decorrer da performance artística reconhecer o cenário e suas histórias.

O meu passado não sei. Nem nunca matuto nele.

Quem vê na noite? O que enxerga na escureza assombrada?

Não recapitular nunca rememorar

Porém num rasgo matinal em coragem perpétua

Ir continuando o que um dia a gente determinou. (p. 57)

O trecho citado acima é uma fala do Poeta, personagem do espetáculo interpretado por Umberto Magnani. A poética da fala revela o tom da obra: o de contar histórias do passado em comprometimento com o presente, tendo como fio condutor os monumentos da cidade edificada junto de seus processos sociais. O roteiro deste espetáculo que aconteceu no centro de São Paulo no dia 18 de dezembro de 1983 é o que dá corpo ao terceiro capítulo da obra que analiso nesta resenha, "Paisagens Paulistanas" de Antonio Augusto Arantes Neto. O terceiro capítulo, assim como a obra como um todo, contém

\footnotetext{
${ }^{1}$ Universidade Federal do Rio Grande do Sul.
} 
uma narrativa fotográfica integrada ao texto com imagens do espetáculo. Rostos pintados de branco com contornos em preto que salientam os olhos e os lábios como em um retrato de filme expressionista, indumentária de época e os corpos em movimento inseridos no grande palco da capital paulista são elementos que compõem as imagens deste capitulo.

Professor titular na Universidade de Campinas (UNICAMP), Antonio Arantes foi presidente do Conselho de Defesa do Patrimônio Histórico, Arqueológico, Artístico e Turístico de São Paulo (CONDENPHAAT) e do Instituto do Patrimônio Histórico e Artístico Nacional (IPHAN). Suas experiências como antropólogo e como gestor de órgãos responsáveis pela manutenção do patrimônio histórico se alinham com o sentido de sua obra que busca compreender a "preservação do patrimônio como prática social" e também formativa do espaço público (p. 10).

"Paisagens Paulistanas" foi publicado no ano de 2002 e fala sobre as estratégias de participação na esfera pública desempenhadas pelos atores sociais. Tendo como princípio a negação da distinção entre espaço urbano e os processos sociais o autor discorre sobre aspectos políticos e culturais da participação no espaço público, abordando temas como memória, paisagem, territorialidades e formação da identidade paulistana. Arantes dedica especial atenção aos temas que lhe são caros, como os embates de cidadania e a relação entre preservação do patrimônio cultural e a formação da nação (p. 10).

O local de referência para a obra é o centro da cidade de São Paulo. Arantes vislumbra a memória da cidade nos anos 1940 e 1950 para pensar as transformações que se processaram nos espaços públicos com a passagem dos anos. O tempo em sua obra é pensado como camadas espaço-temporais que configuram uma dada paisagem, e os lugares como marcos empíricos, reflexivos e afetivos em transformação: "algo que a um só tempo é paisagem e passagem" (p.14). Embora hajam trechos historiográficos, o tempo, a duração e a memória são categorias utilizadas para pensar a história da cidade e os efeitos da passagem do tempo de um modo sensível: "Acontecimentos, espaços e lugares, em mútua articulação, participam da trama que resulta dos trabalhos da memória. Cabe indagar até que ponto e de que forma eles perduram na estruturação das práticas futuras" (p. 21).

"Paisagens Paulistanas" tem como temas principais a construção social do espaço público, os embates de cidadania, as práticas de preservação (p. 10) e os sentidos políticos 
da experiência urbana (p. 11). Sob a égide dessas temáticas, o livro se desenvolve em seis capítulos em uma narrativa que articula fotografias em preto e branco, notícias antigas de jornais, relatos subjetivos, um roteiro de espetáculo teatral e alguns dados de pesquisas quantitativas.

O primeiro capítulo é introdutório, dando um sentido geral à produção da obra. O segundo, intitulado "Primeiro Olhar", é um resgate de lembranças. As regiões do passado são constituídas por idades e planos e cada plano configura um território. As lembranças configuram para o autor, portanto, diferentes territorialidades: "Lembranças são experiências retrabalhadas, conservadas, transformadas, amalgamadas em sonhos, e escrever sobre elas é realizar explorações que cruzam inevitavelmente diferentes planos de realidade" (p. 19).

Contextualizando o momento político da cidade de São Paulo na década de 50, o autor resgata neste capítulo algumas informações do Instituto Brasileiro de Opinião Pública e Estatística (IBOPE). São Paulo via-se "em franca expansão de uma cultura política antivanguardista" (p. 26) e em uma onda de pessimismo sobre a situação econômica do país. A década de 50 também foi marcada pela comemoração do centenário da cidade. A ocasião festiva movimentou a cidade com feiras, exposições, concertos musicais, espetáculos e congressos. A cidade também adquiriu provisoriamente outro visual composto pelas casas e vitrines ornamentadas em celebração.

O terceiro capítulo é composto pelo roteiro do espetáculo "Passos na Cidade" mencionado acima. O capítulo leva no título o nome do espetáculo e contém uma reflexão sobre as implicações de modificações na estrutura da cidade para seus habitantes e os vínculos afetivos e identitários com as estruturas. "Sobreviveria aos efeitos dessa turbulência aquele já tão desgastado marco da paulistanidade?” (p. 47) foi a pergunta que deu início a reflexão sobre a situação do patrimônio edificado no coração da cidade e sua relevância, considerando o viaduto como bem simbólico da população. Com o desenvolvimento acelerado dos grandes núcleos urbanos os lugares de referência pessoal em uma cidade transformam seus significados rapidamente. Ao antropólogo cabe, portanto, estudar os significados desses espaços e edificações ao longo da história.

Meu pai (José Oswald), exemplo de homem público, trabalhou para que a passagem pelo Viaduto do Chá fosse livre. Eles e outros denodados munícipes conseguem libertar o viaduto daquele tributo. Falou-se então que haveria à noite uma 
manifestação pública que viria saudar, entre outros, o meu pai. Comprou-se cerveja. E esperou-se, pela larga noite, a manifestação que não veio. (Fala do Poeta, p. 71)

O capítulo seguinte, "Política de Rua", fala sobre os desafios da pesquisa antropológica em contextos urbanos. A etnologia clássica, afirma o autor, analisa as estruturas culturais que "podem ser inferidas pela observação direta e acompanhamento dos sujeitos nas atividades cotidianas" (p. 85). Já em antropologia urbana, o pesquisador se depara com um objeto cujos limites não coincidem com as fronteiras físicas dos locais onde a pesquisa acontece. Alguns fatores ausentes no contexto estudado podem ser determinantes da análise empírica. Assim, a pesquisa antropológica na cidade impõe seus desafios metodológicos para reconstruir interpretativamente as relações entre espaço urbano e processos sociais (p. 88).

A dimensão do simbólico nem sempre é imediatamente visível na cidade e os rituais são parte dessa dimensão. Algumas práticas referentes ao espaço urbano são rituais no sentido de que armazenam e transmitem informações a seu respeito. As manifestações de rua atualizam padrões e consagram configurações particulares do espaço urbano. Antonio Arantes referencia Edmund Leach para dar conta da dimensão simbólica do espaço urbano: “O ritual confere dimensão cosmológica ou histórica ao que, de outro modo, não seria mais do que prosaicas ocorrências do dia-a-dia” (p. 89). Neste capítulo, além da análise das manifestações como rituais, Arantes também chama a atenção para uma visão das manifestações de protesto, os "saques e quebra-quebras", como performances culturais (p. 102).

"A Guerra dos Lugares", quinto capítulo da obra, se aprofunda na temática da complexidade da experiência urbana e das relações que nela se desenvolvem. Nos espaços da cidade se criam fronteiras simbólicas "que separam, aproximam, nivelam, hierarquizam ou, numa palavra, ordenam as categorias e os grupos sociais" (p. 106). Essas fronteiras são flexíveis e configuram "territorialidades flexíveis" (p. 107), e na convergência dessas territorialidades se criam zonas de contato onde se desenvolvem os conflitos, que foram chamados por Arantes de "sociabilidades marginais".

Cada territorialidade possui suas moralidades e sociabilidades próprias. No ato de caminhar e se deslocar pela cidade acontece sobreposição e entrecruzamento dessas zonas simbólicas de transição (p. 106). Arantes utiliza o conceito de Victor Turner para designar esse cruzamento de atores e cenários como limiares. As zonas de contato - ruas e praças - são um ambiente onde se condensam distintas moralidades, por vezes conflitantes. 
Deste modo, Arantes caracteriza as zonas de convergência como espaço onde se explicitam os conflitos de "uma sociedade fragmentada em guerra consigo mesma" ( $p$. 129).

Por fim, no capítulo "Desigualdade e Diferença", os contrastes, as diferenças e as oposições identificados nos espaços comuns são abordados juntamente à problemática da cidadania. Segundo o autor, cidadania está relacionada ao sentimento de pertencer, de onde surge a ideia de comunidade (p. 132) e também a possuir uma localização no mapa social (p. 133). O cidadão, portanto, se constitui a partir de um lugar e uma situação social. Os embates de cidadania geram transformações no espaço e na estrutura social. Em contextos urbanos onde impera a diversidade, um sujeito pode agregar em si múltiplas identidades e se sentir membro de diferentes agrupamentos sociais: "A participação no processo social se dá não a partir de apenas um, mas resulta do conjunto desses vários eixos, cada um dos quais possuindo estatuto político próprio" (p. 136).

Disso decorre a problemática da gestão das diferenças conflitivas no espaço público: "de que modo se pode manejar democraticamente tais diferenças?” (p. 139). Arantes sugere um caminho para pensar essa problemática referenciando o teórico indiano Hommi Bhabha: "uma coletividade política só pode, ao mesmo tempo, articular a diferença e conviver com ela, se estiver enraizada numa noção não imperial ou não totalizadora de self" (p. 144).

Este capítulo também aborda o fenômeno da diferenciação entre classes que se acentuou na cidade a partir dos anos 80 . O padrão centro-periferia dos anos 40 mantinha a população mais pobre afastada do centro, afirma Arantes. Com o passar do tempo essas fronteiras foram se mostrando permeáveis, evidenciando novos desafios no horizonte dos conflitos da esfera pública. As "novas paisagens de poder e exclusão (...) tendem a dar lugar a um novo código de relacionamento na desigualdade” (p. 149). A atualização da linguagem nas diferenças e na desigualdade faz do espaço público um lugar político (p. $151)$.

Nessa obra o espaço público do centro de São Paulo é retratado como lugar de estruturação flexível de identidades e de práticas de cidadania. A cidade é feita de paisagens políticas que se formam e se transformam atribuindo significados aos processos históricos da cidade. O livro é uma importante contribuição no debate antropológico sobre os bens e valores materiais e culturais de uma nação referentes ao espaço público. O olhar 
antropológico sobre os monumentos da cidade e o passar do tempo mostra o que nem sempre é óbvio: a importância dos lugares que se tornam referência pessoal e simbólica para os habitantes na construção de uma identidade paulistana. Em uma narrativa composta por elementos de naturezas distintas - fotografias, matérias de jornais, relatos diversos, etc. - que criam uma linguagem acessível à diversos públicos a obra foi bem sucedida em evidenciar, através da antropologia na cidade, a ponte que conecta as estruturas urbanas edificadas às relações sociais que com elas se desenvolvem. 